maternity departments, where general practitioners can treat their own patients. The private hospitals are independent, but the State controls several technical aspects of their work, and most of them have entered into agreements with the social security system whereby patients are reimbursed according to tariffs fixed annually.

In France the right to health care, whenever it is received, is guaranteed and financed by different systems covering different risks-for example, illness, maternity, disability, and accidents at work. Patients pay for their medical care and are then reimbursed in part or in whole under one of the various insurance schemes (see table.) Medical Care Insurance also pays sickness benefits to employees; medical care for accidents at work is free and there is a disability insurance scheme under which patients receive a pension.

Reimbursements by French Society System

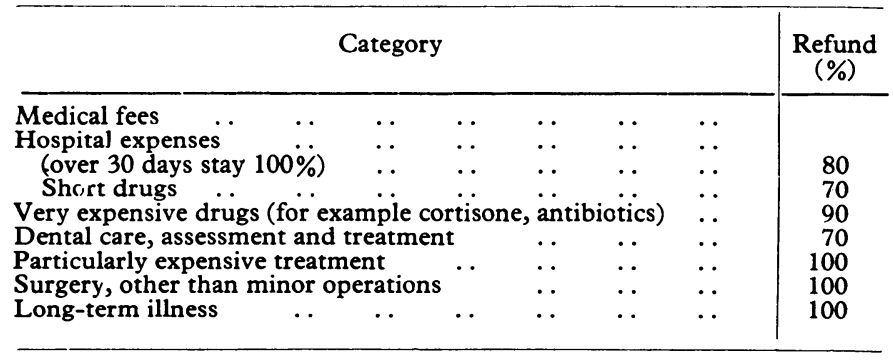

\section{Social Security}

Social security in France is a collective and compulsory system of protection against certain risks. It is not a government agency but an autonomous body, whose boards include an equal number of representatives of the employers and of the trade unions. Both employers and workers contribute to the scheme-thus for a monthly salary of about $£ 200$, the respective percentages contributed are 10.25 and 2.5 of the salary.

What are the benefits of membership of the E.E.C. to the individual patient? Since October 1972 the reciprocal social security arrangements have meant that an Englishman or a German living permanently in France, or on holiday, has had the same advantages as a Frenchman.

He has only to produce the certificate proving that he is covered by the insurance system in his home country. A clearing system has been set up between the various social agencies to settle financial problems, and these arrangements already cover two and a half million people. A Frenchman will also be able to receive hospital care in another member's state and to have his expenses paid provided he is covered by the French social security system. This benefit is not yet available to foreigners in France.

There is still a long way to go before total "harmonization" is achieved and I believe that the patient will not benefit fully until agreement has been reached on the question of the free circulation of doctors within the community. This proposal has received much opposition but $I$ have travelled through most of the countries of the community and I do not think that the health of the various populations differs notably from one to the other. Instead of the endless meetings where the comparative value of curricula and specialist training programmes are discussed, I would suggest a European survey, by an international panel of epidemiologists on, for example, the way in which five or six medical or surgical emergencies, and five or six chronic diseases are treated in the community. We should be surprised by the similarity of the methods employed and the results obtained.

I believe that the European Community has no real meaning unless its human and social aspects are enhanced as well as the economic ones. Medicine can and should play an important part in achieving this.

Créteil, France

J. L. PORTOS, M.D., Professor of Medicine

\section{The Netherlands}

\section{L. C. VAN NIEUWENHUIZEN}

Within the E.E.C. all employees in other member states staying for less than 12 months in the host country continue to be insured by their home country, but receive medical attention under the prevailing insurance system of the host country. If the employee stays in the Netherlands longer than 12 months he will be admitted to our insurance system and will have to pay his share of the premium.

In the Netherlands, as in the U.K., the patient visits the specialist via the general practitioner (though in exceptional cases a private patient may apply to the specialist directly). Medical specialists are registered by the Royal Netherlands Medical Association, whose Central College produces a list of recognized specialties, and lays down rules for training, which is recognized both by the social security system and by the hospitals. Since 1930 the Royal Medical Association has been responsible for registering specialists, through a special committee. The Central College, however, does more; among other things it has examined the distribution of specialists in the Netherlands, of their ages and when they will need to be replaced.

If I have learned anything during the fifteen years I have been studying the guide lines for the free establishment of the liberal professions, then it is that we should not prejudge the value of the systems in other countries. Thus I was no little surprised that the attitude of British doctors towards the E.E.C. was just the same as I had observed among the doctors' representatives in the Six some 10 or 12 years ago; they were afraid of a mass invasion of doctors from abroad and that the standard of medical treatment would be lowered in their country. For this reason demographic examinations are of vital importance. The National Hospital Institute is an independent scientific body of the Dutch hospitals and may be compared with your King's Fund. Their report on the distribution of hospital specialists, which was commissioned by the Central College, contains a wealth of information, and if we had a similar account for every country we could make some forecasts about the movement of specialists within Europe. Similar statistics for health care as a whole might also be just as important. Nevertheless, such problems cannot be solved by doctors alone, but need a team including statisticians, epidemiologists, and planning specialists.

Utrecht, The Netherlands

C. L. C. VAN NIEUWENHUIZEN, M.D., Cardiologist

\section{Denmark}

\section{AAGE PEDERSEN}

Under certain circumstances many of the benefits available to Danish patients are also available to those of other member states in the Common Market; moreover, I am convinced that some of the Danish "arrangements" may have some influence on the directives to be issued by the council in Brussels.

For years Denmark as well as the other Scandinavian countries, the United Kingdom, France, West Germany, and Switzerland, have been signatories to agreements on social security. For example, the agreement between the United Kingdom and Denmark applies to such things as health insurance, national pensions, disablement annuities, unemployment insurance, widows' pensions, and child welfare. Despite these agreements there were so many differences remaining between countries that the Council of Ministers had to issue a decree about employees and their families who had moved from one country to another within the Common Market. This defined an "employee" as "any person who is insured in pursuance of the compulsory insurance arrangement or in pursuance of a voluntary permanent insurance against one or several risks, in conformity with the various branches of insurance incorporated in a social security arrangement." 